\title{
O que narram os historiadores? Para uma genealogia da questão narrativa em história ${ }^{1}$
}

\author{
Jurandir Malerba*
}

Pontifícia Universidade Católica do Rio Grande do Sul, Porto Alegre - RS, Brasil

\section{RESUMO}

O argumento deste artigo é o de que a discussão em torno do caráter e da função da narrativa histórica vinha se desenvolvendo numa clave específica pela filosofia analítica anglo-saxônica, cuja linha de pensamento e argumentação fora nitidamente abandonada em poucos anos com a irrupçáo do paradigma linguístico pós-estruturalista, e, paralelamente das teses do crítico literário norte-americano Hayden White, no início dos anos 1970. A ruptura nessas linhas de reflexão acabou obliterando o potencial da reflexão que vinha se desenvolvendo antes que todas suas premissas fossem exauridas. Na primeira parte deste texto relata-se um debate recente entre dois expoentes da filosofia da história. Em seguida, uma breve recensão bibliográfica acerca do tema da narrativa histórica na perspectiva da filosofia analítica.

Palavras-chave: narrativa histórica; narrativismo; filosofia analítica da história; filosofia analítica da linguagem; teoria da história.

\section{ABSTRACT}

In this paper it is argued that the debate on the nature and function of historical narrative developed under a specific key for Anglo-Saxon analytical philosophy, whose line of thought and argument was clearly abandoned a short time due to the emergence of the paradigm linguistic poststructuralist and, in parallel, the theses of the American literary critic Hayden White, in early 1970s the break in these lines of thought led to the abandonment of reflection before all its potential to be explored. In the first part of this text we report a recent debate between two exponents of the philosophy of history. Then a brief literature review about the historical narrative theme from the perspective of analytical philosophy is given.

Keywords: historical narrative; narrativism; analytic philosophy of history; analytic philosophy of language; theory of history.

DOI - http://dx.doi.org/10.1590/2237-101X017033004

Artigo recebido em 30 de junho de 2015 e aprovado para publicação em 10 de novembro de 2016.

${ }^{1}$ Uma primeira versão deste texto foi originalmente apresentada na VII Jornada de História e Historiografia: História e Filosofia, UFRGS, em 12/06/2015. Agradeço a todos participantes pelos comentários críticos e sugestóes e nominalmente a Fenando Nicolazzi, Temístocles Cézar, Marcelo Jasmin, Marcelo Rangel e Hélio Rebello Cardoso Jr.

* Doutor em História Social pela USP, professor da PUCRS e pesquisador do CNPq. E-mail: Jurandir.malerba@pucrs.br. 
A verdade do acontecimento baseia-se na complementação a ser feita pelo historiador ao que chamamos acima de parte invisível do fato. Visto por este lado, o historiador é autônomo, e até mesmo criativo; e não na medida em que produz o que não está previamente dado, mas na medida em que, com sua própria força, dá forma ao que realmente é, algo impossível de ser obtido sendo meramente receptivo. De um modo diverso ao do poeta, mas, ainda assim, guardando com este semelhanças, o historiador precisa compor um todo a partir de um conjunto de fragmentos.

Wilhelm von Humboldt ${ }^{2}$

A história distingue-se de todas as outras ciências por ser também uma arte. A história é uma ciência ao coletar, buscar, investigar; ela é uma arte porque recria e retrata aquilo que encontrou e reconheceu. Outras ciências satisfazem-se simplesmente registrando o que foi encontrado; a história requer a habilidade para recriar. Como ciência, a história é parecida com a filosofia; e como arte, com a poesia. A diferença é que, de acordo com suas naturezas, filosofia e poesia lidam com o reino do ideal, enquanto a história deve ater-se à realidade.

Leopold von Ranke ${ }^{3}$

\section{Introdução}

Poderia soar extemporâneo abrir-se uma discussão filosófica sobre o caráter da narrativa histórica com epígrafes de Humboldt e Ranke, dois ícones da tradição histórica germâni-

\footnotetext{
${ }^{2}$ HUMBOLDT, Wilhelm von. Sobre a tarefa do historiador. Tradução Pedro Caldas. Anima: História, Teoria e Cultura. Rio de Janeiro/Curitiba, ano 1, n. 2, p. 79-89, 2001. Reproduzido em MARTINS, Estevão C. R. A história pensada. São Paulo: Contexto, 2009. Neste volume, vale a pena conferir a excelente "Sobra a tarefa do historiador, de Wilhelm von Humboldt: Uma apresentaçáo”, de Pedro Caldas.

${ }^{3}$ RANKE, Leopold von. Sobre o caráter da ciência histórica. Tradução Julio Bentivoglio. In: MALERBA, Jurandir. Liçóes de história. O caminho da ciência no longo século XIX. Porto Alegre/Rio de Janeiro: EdiPucrs/ Editora FGV, 2010, p. 141. Conferir a introduçáo de Julio Bentivoglio, "Leopod von Ranke", naquele volume, p. 132-141.
} 
ca do século XIX, tidos (muitas vezes apressada e equivocamente) como basilares de um "positivismo" ou de um empirismo ingênuos que a sucessão do tempo faria logo e naturalmente superados. Minha geração formou-se no campo da história quando ela se cria indiscutivelmente, apoditicamente, uma ciência social! "Filosofia da história” remetia a um passado remoto e conservador, dos iluministas até Hegel, pensadores que se dedicavam a especular sobre o curso, o sentido e o motor da história. Tolerava-se autores como Agnes Heller ou Henry Marrou, que diferenciavam essa filosofia especulativa de uma "filosofia sobre a história", aquela atividade de reflexão sobre o conjunto de questôes e protocolos em torno da produção da história como conhecimento científico. Neste caso, tratando-se de tópicos como tempo, espaço, indivíduo, classe, estrutura, acontecimento, determinação, soava mais apropriado falar de "teoria", em vez de "filosofia". Nos extremos do espectro, quando a ideia da história como ciência estava por assim dizer naturalizada, não eram poucos os que trabalhavam em torno dos tópicos relativos a uma "epistemologia da história", para abordar questôes como neutralidade, objetividade, verdade histórica e questóes de ordem metodológica, particularmente vinculadas aos métodos quantitativos e à seriação.

Filosofia era quase um palavrão. Infelizmente, durante minha formação, eu não tive notícia de outros ramos da filosofia que incidiram tão diretamente na reflexão teórica ao longo do século XX, dos quais, por todos, menciono apenas dois. Por um lado, o debate em torno da hermenêutica filosófica performado por Gadamer e Habermas; ${ }^{4}$ por outro, o locus onde a reflexão teórica talvez mais e melhor se desenvolvia, aquela que imantava o conjunto diverso

\footnotetext{
${ }^{4} \mathrm{Na}$ introdução de Verdade e método, Hans-Georg Gadamer refere a uma verdade inalcançável por meio de uma metodologia científica. Aquela verdade que surge com a experiência, seja a experiência da filosofia, da arte ou da própria história e, a partir desse conceito de verdade, critica "a pretensão de universalidade da metodologia científica" para propor um conceito de conhecimento e de verdade relacionados ao todo da experiência do ser humano no mundo, que coincide com própria experiência hermenêutica. Nesse universo "verdadeiramente hermenêutico", entram ingredientes como "o modo como experimentamos uns aos outros, como experienciamos as tradiçóes históricas, as ocorrências naturais de nossa existência e de nosso mundo", ao qual estamos ligados pela linguagem e pelo pensamento. Jürgen Habermas, não obstante considerar superior a hermenêutica gadameriana vis-à-vis a filosofia da linguagem de Wittgenstein e a fenomenologia, crítica a pretensão de universalidade da hermenêutica de Gadamer. "O argumento de Habermas contra Gadamer pode resumir-se na afirmação de que, apesar de a compreensão hermenêutica ser um primeiro passo necessário na compreensão, não pode ser o último" Cf. HEKMAN, Susan Jean. O debate Gadamer-Habermas. In: HEKMAN, Susan Jean. Hermenêutica e sociologia do conhecimento. Lisboa: Edições 70, 1986, p. 187-198. Cf. GADAMER, Hans-Georg. Verdade e método. Petrópolis: Vozes, 2001/2002. 2v.; KOSELLECK, Reinhart; GADAMER, Hans-Georg. Historia y hermenéutica. Barcelona: Paidós, 1997; HABERMAS, Jürgen. La lógica de las ciencias sociales. Madri: Tecnos, 1988. O debate é sumarizado em IGGERS, Georg. La ciencia histórica en el siglo XX. Las tendencias actuales. Barcelona: Paidós, 1995; GUADARRAMA, José Luís. El debate Gadamer-Habermas: interpretar o transformar el mundo. Contribuciones desde Guatepec, n. 10, p. 11-21, jan./ jun., 2006; HEKMAN, Susan Jean. O debate Gadamer-Habermas. In: HEKMAN, Susan Jean. Hermenêutica e sociologia do conhecimento. Lisboa: Ediçóes 70, 1986, p. 187-198; BATISTA, Micheline. Hermenêutica filosófica e o debate Gadamer-Habermas. Crítica e Sociedade: Revista de Cultura Politica, v. 2, n. 1, jan./jun. 2012; GRONDIN, Jean. Introducción a la hermenêutica filosófica. Barcelona: Herder, 2002 e RICEUR, Paul. Del texto a la acción. México: Fondo de Cultura Económica, 2002.
} 
de autores conhecidos como filósofos analistas da história, que veiculavam suas reflexóes em livros e numa revista específica, a History \& Theory. Então, no final dos anos 1970 e ao longo dos anos 1980, historiador com "H" maiúsculo no Brasil era aquele que, sem se limitar exclusivamente à pesquisa empírica, para não ser expurgado como "positivista" (como se o positivismo não fosse uma filosofia!), era capaz de conjugar pesquisa empírica com a oferta de explicaçôes causais a quaisquer sequências de eventos históricos. A filosofia da história praticamente não compunha na formação dos historiadores no Brasil.

Um divisor de águas nessa história intelectual foi o chamado giro linguístico. ${ }^{5} \mathrm{E}$ ele foi decisivo porque em poucos anos aquela segurança de que a história existe ontologicamente e pode ser conhecida cientificamente sofreu uma série de abalos tectônicos, dos quais não mais se recuperou. $\mathrm{O}$ foco da metarreflexão deixou de ser a história processo ou os parâmetros da pesquisa metodicamente regulada para recair sobre os protocolos constitutivos do discurso historiográfico. Não sem alguma ironia, esse deslocamento gerou uma avalanche de reflexão teórica, metateórica, filosófica, ou como se queira chamar, como jamais haviam conhecido os historiadores. Todos em busca do que se trata, ao fim e ao cabo, aquilo que resulta do trabalho de pesquisa, mas, sobretudo, do que Ricouer chamou da "fase escritural" do trabalho do historiador. ${ }^{6}$

Desde entâo, geraçôes de filósofos e teóricos da história passaram a pensar diuturnamente seu estatuto. Mas desde uma geração ou duas antes, digamos, pós-Collingwood, muitos já vinham procurando fazer sentido da natureza do discurso historiográfico, desde os pensadores inseridos no debate sobre a função explicativa da narração histórica até, posteriormente, as versôes mais radicais que concebem a história como constituída do, no e pelo relato per se. Esses debates parecem velhos e, de fato, talvez o sejam. Mas creio que muito longe estâo de esgotados. Para demonstrá-lo, e para mostrar que a questão narrativa em história apresenta desafios muito distantes de qualquer solução "definitiva", na primeira parte deste texto permitir-me-ei contar uma breve anedota, relatando um debate cruento que tive a oportunidade de presenciar recentemente entre dois expoentes da filosofia da história. A partir dela - e este é o escopo deste artigo — apresentarei uma hipótese heurística sobre a história da reflexão teórica em torno da narrativa. Na segunda parte, por

\footnotetext{
${ }^{5}$ Recentemente não são poucos os autores que, buscando “delimitar o campo", enxergam outro "giros": memorial, ético/moral, do sujeito etc.; mas nenhum foi decisivo quanto o linguístico!

6 "Se o papel epistemológico maior se desenrola na fase da explicação compreensão, não se pode omitir que é na fase escritural que se declara plenamente a intenção do historiador, a de representar o passado tal como ele se produziu - qualquer que seja o sentido que se atribua a "tal como". “(...) Eu prefiro finalmente o termo 'fase', na medida em que, na ausência de uma ordem cronológica [da investigação] de sucessáo, ele sublinha a progressão da operaçáo quanto à manifestação da intenção historiadora de reconstrução verdadeira do passado (170/1). Náo é senáo na terceira fase, com efeito, que se declara abertamente a intenção de representar a verdade das coisas passadas, por que se define face à memória o projeto cognitivo e prático da história tal como a escrevem os historiadores de ofício." RICCEUR, Paul. La Mémoire, L'Histoire, L'Oubli. Paris: Éditions du Seuil, 2000, p. 169-171.
} 
fim, oferecerei uma breve recensão bibliográfica acerca do tema da narrativa histórica na perspectiva da filosofia analítica.

\section{Narrativa histórica: atualidade de uma aporia teórica}

Era 11 de julho de 2013, uma linda quinta-feira de sol no aprazível verão de Ghent, a cidadela medieval belga cuja universidade secular recebeu a primeira conferência da International Network for the Theory and Philosohy of History. Conferencistas e painelistas de primeiro escaláo abrilhantavam o evento, um festejado evento que representaria, para muitos, a consolidação derradeira dessa área desde sempre marginalizada pelos historiadores de ofício; para outros, talvez o canto do cisne. Com tantos filósofos confinados em espaço tão diminuto, natural foi que de tudo um pouco se ouviu. Mas talvez nenhum embate sintetize melhor o espectro de posições e entendimentos - e uma polarização básica — sobre o que resulta do trabalho dos historiadores do que um debate visceral, ocorrido naquele evento. $\mathrm{Na}$ seção 18, "Debating Historical Experience I", o filósofo Paul Roth apresentou uma comunicaçáo que consistia num ataque irado contra as premissas enunciadas pelo célebre filósofo narrativista holandês Frank Ankersmit no seu último livro: Meaning, Truth, and Reference in Historical Representation, de 2012.7 O que talvez Roth não esperasse é que Ankersmit seria o comentador daquela seção e trouxe sua réplica já impressa para distribuir à audiência.

Roth foi impiedoso. Começou dizendo que ninguém escreveu mais nas últimas três décadas sobre certos temas na filosofia da história que Frank Ankersmit. No entanto, praticamente ninguém, senão o próprio Ankersmit, reivindicaria a necessidade de uma "filosofia da história", tal como ele a concebe - ou seja, aquela em que "história" designaria uma forma sui generis de conhecimento, de modo que "filosofia da história" referir-se-ia a uma disciplina que precisa articular seus próprios princípios especiais de representação, experiência, verdade, significado e referência. Para Roth, ainda, Ankersmit vem trabalhando ao longo de décadas para encontrar resposta satisfatória a uma questão que ele mesmo formulou e só a ele interessa. Mas lhe faltaria um exame rigoroso da filosofia da linguagem contemporânea.

Porém, se o livro do consagrado filósofo holandês Meaning, Truth, and Reference se propóe a corrigir aquela falta, para Roth não o alcança. Com relação às questóes gerais em pauta, afirma Roth, a filosofia da história de Ankersmit só se sustentaria se se descartar o que ele diz sobre a filosofia analítica da linguagem. No sentido oposto, a abordagem da representaçáo histórica de Ankersmit só se sustentaria se e quando apoiada em seus próprios pressupostos. Sem eles, sua defesa filosófica do historicismo se esboroaria, junto com todo seu projeto narrativista. Enfim, ancorado numa leitura bastante "ao pé da letra" de filósofos da ciência e da

\footnotetext{
${ }^{7}$ ANKERSMIT, Frank Rudolf. Meaning Truth, and Reference in Historical Representation. Ithaca, NY: Cornell University Press, 2012.
} 
linguagem protagonistas ou tributários do Círculo de Viena, como Rudolf Carnap, Donald Davidson, Wilfrid Sellars e, particularmente, Willard Van Orman Quine, Paul Roth tenta jogar no lixo a obra de Ankersmit. Mas este não se dá por logrado e imediatamente apresenta sua réplica.

O contra-argumento central de Arkersmit jaz em demonstrar como o suposto antidogmatismo cria dogmatismo. Para Ankersmit, a leitura que Roth faz de sua obra é uma radicalizaçâo de algo a la "como Quine leria Ankersmit?", mas um Quine deturpado, deformação de um discípulo limitado. Para Ankersmit, o pós-positivismo de Quine foi, principalmente, um ataque ao dogmatismo da filosofia fundamentalista da linguagem e da ciência, que reivindicava oferecer uma abordagem apriorística do conhecimento e da relação entre a linguagem e o mundo. Em oposição a esse dogmatismo, o pós-positivismo de Quine exigia do filósofo da linguagem e da ciência respeitar e estar aberto à forma como, na prática da ciência, o conhecimento pode surgir. Para Ankersmit, a revisão que Roth fez de seu livro é um ótimo exemplo de como o antidogmatismo de Quine pode se tornar ele mesmo um dogma.

Basicamente, por recusar-se a reconhecer a imensa variedade existente nas práticas da ciência e, consequentemente, que cada ciência pode e deve ter a sua própria prática. No caso de Roth, essa má vontade teria resultado na projeção de certo conceito de ciência sobre a história e as ciências humanas. Isso o obrigou, talvez sem o desejar, a abraçar o dogma da unidade da Ciência. Esse debate remonta ao final do século XIX, posicionando de um lado defensores da ideia de uma razão científica única aplicável a todo e qualquer campo do conhecimento, inclusive a história (essa ala foi alcunhada de "positivista"); e, de outro, os defensores da existência de um nicho epistemológico próprio para as ciências do espírito (essa é a postura dos historistas, como Dilthey). ${ }^{8}$

Náo é o caso descermos ponto a ponto nos argumentos de ambos contendores. ${ }^{9}$ Roth acusa Ankermit de compartilhar da velha ideia de história universal, de desconsiderar e/ ou ler erradamente os filósofos da linguagem, de ingenuamente recuar em suas posiçóes anteriores ao conceber a possibilidade de uma "interpretação verdadeira" de uma quimérica "experiência não linguística ou pré-linguística" da realidade passada, ${ }^{10}$ de que a noção de

\footnotetext{
${ }^{8}$ Peças-chave desse debate, que contempla autores como Wilhelm Dilthey, Karl Lamprecht, Wilhelm Windelband, Heinrich Rickert, mas também Max Weberf e Georg Simmel, encontram-se traduzidas e comentadas por grandes especialistas como José Carlos Reis, Sérgio Duarte, Carlos Oiti Berbert Jr., Sérgio da Mata, René Gertz e Pedro Caldas em MALERBA, Jurandir. Liçôes de história. Da história científica à crítica da razão metódica. Porto Alegre/Rio de Janeiro: EdiPucrs/Editora FGV, 2013.

${ }^{9}$ Os dois textos foram imediatamente publicados. CF. ROTH, Paul A. Whistling history: Ankersmit's neoTractarian theory of historical representation. Rethinking History: The Journal of Theory and Practice, v. 17, n. 4, p. 548-569, 2013. ANKERSMIT, Frank Rudolf. Reply to professor Roth: on how antidogmatism bred dogmatism. Rethinking History: The Journal of Theory and Practice, v. 17, n. 4, p. 570-585, 2013. Agradeço a um dos organizadores do evento, Kalle Pihlainen, por disponibilizar-me esse material.

10 "Ankersmit's notion of non-propositional representation has as its 'goal' nothing less than referring to 'past reality itself', to 'cross the language/world barrier'”, ROTH, Paul A. Whistling history: Ankersmit's neoTractarian theory of historical representation, op. cit., p. 560.
} 
representação de Ankersmit recua ao conceber uma inefável articulação entre linguagem/ conhecimento/passado-como-realidade-histórica e assim por diante. De fato, o mal-estar de Roth é compreensível se lembrarmos que Ankersmit fez seu nome no meio filosófico como o mais aguerrido defensor das teses narrativistas de Hayden White. Durante três décadas, Ankersmit foi um militante da desreferencialização da história. ${ }^{11}$ Se retomarmos trabalhos anteriores de Ankersmit, ${ }^{12}$ a alteração de perspectiva, evocando dois teóricos realistas como Humboldt e Ranke, fica patente - e talvez explique a indignação de Roth.

O nome de Frank Ankersmit merece especial destaque dentre os grandes divulgadores do narrativismo de Hayden White. A categoria central de Ankersmit é a narratio, "uma forma definida de modo amplo que contém muitos modos específicos de discurso". Os três eixos da lógica narrativa que propóe são (1) que não existem regras de tradução da realidade, (2) que é o todo da narratio, mais do que a soma de suas sentenças narrativas, que é a substância narrativa capaz de fornecer a chave para a interpretação do passado, e (3) que existe uma similaridade entre afirmações históricas e metafóricas. Não é o "passado", mas nosso entendimento de substâncias narrativas que tem uma estrutura narrativa; ainda que o próprio "passado" tivesse uma estrutura narrativa, nós não poderíamos conhecê-la, porque não existem regras de traduçáo que nos permitam verificar qualquer correspondência entre o que se passou e as sentenças narrativas propriamente ditas. ${ }^{13}$ Junto com Ankersmit, outro grande divulgador do narrativismo é o filósofo Hans Kellner. Uma súmula de suas ideias pode ser encontrada em Language and Historical Representation, de 1989, onde Kellner atualiza ideias já publicadas em trabalhos anteriores e agrega novas reflexôes. Numa perspectiva geral, Kellner sustenta que, para se conseguir realmente enxergar o texto de história, deve-se "desfocar" a leitura, uma vez que a "ideologia da verdade" do historiador reza que

${ }^{11}$ Trata-se do princípio básico da desreferencialização, segundo o qual o passado não é e não pode ser o referente das afirmaçóes dos historiadores. Cf. ANKERSMIT, Frank Rudolf. Narrative Logic: A Semantic Analysis of the Historian's Language. The Hague: Nijhoff, 1983. Também ANKERSMIT, Frank Rudolf. History and Tropology: The Rise and Fall of Metaphor. Berkeley: University of California Press, 1994b. E ANKERSMIT, Frank Rudolf. Historical Representation. Stanford: Stanford University Press, 2001. Outros exemplos, menos articulados e consistentes, mas mais barulhentos, são BERKHOFER Jr., Robert. "The Chellenge of Poetics to (Normal) Historical Practice". In: JENKINS, Keith (Org.). The Postmodern History Reader. Londres/Nova York: Routledge 1997 e o próprio Jenkins, Introduction: On Being Open about our Closures, na mesma obra.

${ }^{12}$ ANKERSMIT, Frank Rudolf. History and Tropology. Berkeley: Universiy of California Press, 1994a; ANKERSMIT, Frank Rudolf. The Dilemma of Contemporary Anglos-Saxon Philosophy of History. History \& Theory, n. 25, p. 26, 1986.

${ }^{13}$ Cf. ANKERSMIT, Frank Rudolf. Narrative Logic: A Semantic Analysis of the Historian's Language, op. cit.; ANKERSMIT, Frank Rudolf. Six Theses on Narrativist Philosophy of History. In: ANKERSMIT, Frank Rudolf. History and Tropology, op. cit.; ANKERSMIT, Frank Rudolf. History and Tropology: The Rise and Fall of Metaphor, op. cit.; ANKERSMIT, Frank Rudolf. Historical Representation, op. cit. Ainda, o famoso livro de divulgaçáo da proposta narrativista editada conjuntamente por Ankersmit e Kellner, 1985 (há uma outra edição pela Chicago: University of Chicago Press, 1995). Ver também o sofisticado livro editado por Carrard1992. 
nós devemos enxergar, através do texto histórico, a realidade histórica que ele pretende representar. Realidade que, a rigor, o historiador jamais alcançará. ${ }^{14}$

Quando relembramos as teses narrativistas que fizeram sucesso nos anos 1980/1990, causa mesmo espécie quando Ankersmit começa seu Meaning, Truth, and Reference in Historical Representation fazendo quase uma mea culpa de sua obra pregressa, ao afirmar que Humboldt e Ranke estavam certos e que a posteridade se precipitou em crucificá-los; de que sim, existe uma realidade histórica passada, que os historiadores buscam representar narrativamente; que existe uma verdade do passado (como realidade), embora todo esforço do historiador será sempre insuficiente para alcançá-la e assim por diante. Desde o século XIX, uma legiáo de pensadores — leia-se, de filósofos! — vem buscando resposta para essas questôes relativas ao exercício da prática histórica. Afinal, o que fazemos nós, historiadores? O que resulta de nosso ofício? Que tipo de conhecimento do passado oferecemos? Os historiadores somos contadores de história? Podemos nós pretender contar estórias verdadeiras sobre o passado? A que nossas histórias (estórias?) se referem? Qual o sentido de verdade possível de uma narração histórica? Como nós historiadores procedemos para fazermos sentido do passado como história? Qual a potencialidade de explicação dos fatos passados pelos historiadores presentes? Quais as especificidades — se elas existirem — que distinguem um texto histórico de um texto ficcional?

Essas são questôes centrais de um debate permanente ao longo do século XX, levado a cabo, sobretudo, por filósofos e teóricos - em geral os historiadores de ofício rejeitam essas questôes! Esse debate ganhou uma coloração muito diversa a partir da década de 1970 e que baliza a discussão atual em torno das implicaçôes práticas dessas reflexôes filosóficas sobre a escritura da história. Ao longo do século XX, quando a crença numa história ciência social era hegemônica, a discussão teórica em geral centrou-se justamente nas implicaçôes da pesquisa cientificamente orientada, fundada em suporte documental, depositando-se maior ênfase nos aspectos metodológicos da produçáo do conhecimento histórico. A pauta que se estabeleceu já desde os anos 1960 poderia ser enunciada assim: em que medida a disciplina da história é, em sua essência, um modo de conhecer, compreender, explicar e reconstituir/ reatualizar o passado?

No que se refere à questão da narrativa no conhecimento histórico, o foco do debate desde os anos 1960 gira em torno de se, em que medida, (A) a narrativa histórica é um modo de explicaçáo. ${ }^{15}$ Este debate tornou-se chave entre aqueles que enxergam as narrativas

\footnotetext{
${ }^{14}$ KELLNER, Hans. Language and Historical Representation: Getting the Story Crooked. Madison: University of Wisconsin Press, 1989. Ainda, o famoso livro de divulgação da proposta narrativista editada conjuntamente por Ankersmit e Kellner, ANKERSMIT, Frank Rudolf; KELLNER, Hans. A New Philosophy of History. Londres: Reaktion, 1985 (há uma outra edição pela University of Chicago Press, 1995). Ver também o sofisticado livro editado por CARRARD, Philippe. Poetics of the New History: French Historical Discourse from Braudel to Chartier. Baltimore: Johns Hopkins University Press, 1992.

${ }^{15}$ Cf. ROBERTS, Geoffrey. Introduction. The History and Narrative debate, 1960-2000. In: ROBERTS, Geoffrey (Ed.). The History and Narrative Reader. Londres/Nova York: Routledge, 2001, p. 1-21.
} 
históricas como explicaçôes protocientíficas do passado que podem ser formalizadas e analisadas; e aqueles que enfatizam o papel das narrativas para o aumento da inteligibilidade e do conhecimento da história. ${ }^{16}$ Uma segunda pauta em torno da narrativa concerne ao trabalho daqueles historiadores, teóricos e filósofos que sustentam que (B) as narrativas sáo histórias de ação e que é a consideração da ação humana em termos narrativos que torna os estudos históricos plenos de sentido e os constituem em explicaçôes significativas do passado humano. ${ }^{17}$ Uma terceira área de reflexão sobre o papel da narrativa em história, (C) sobre o realismo histórico, explora a questáo de que a razão pela qual os historiadores constroem histórias sobre o passado é que essas histórias refletem a própria vida, a consciência e a existência humanas, as quais têm em si uma natureza e um caráter narrativo. ${ }^{18}$ Desde a década de 1960, porém, esse debate se acirrou por causa do linguistic turn, a partir do qual se passou a argumentar que a construção da narrativa histórica nada tem a ver com a experiência dos homens no tempo, com as açôes humanas passadas, nem com fontes ou metodologias científicas de pesquisa, mas é totalmente guiada por protocolos linguísticos e que as histórias contadas pelos historiadores são, em grande medida, (D) consideraçóes

\section{literárias e ficcionais sobre passado.}

Como afirmou em 1978 Lawrence Stone em seu clássico ensaio sobre o retorno da narrativa, "os historiadores sempre contaram estórias", mas não foi senão a partir dos anos 1960 que os filósofos começaram a prestar atenção à questão da natureza e função das narrativas históricas. Por certo que a narrativa nunca foi totalmente negligenciada pelos filósofos da história, ${ }^{19}$ mas os poucos tratamentos dados à questão tendiam a ser ofuscados por debates filosóficos tradicionais sobre os problemas da objetividade, da explicação e da causalidade nos estudos históricos. ${ }^{20}$

A mudança de percepção da questão narrativa na filosofia da história foi, em parte, resultado de algumas contribuiçôes importantes por autores como Morton White, Arthur

\footnotetext{
${ }^{16}$ Por exemplo, entre outros: GARDINER, Patrick. The Nature of Historical Explanation. Londres: Oxford University Press, 1954; GALLIE, Walter Bryce. The Historical Understanding. History and Theory, v. 3, n. 2, p. 149-172, 1963; DRAY, William Herbert. Philosophy of History. Nova York: Prentice-Hall, 1964; MANDELBAUM, Maurice. A Note on History as Narrative. History and Theory, v. 8, n. 2, 1966; ATKINSON, R. F. Knowledge and Explanation in History: an Introduction to the Philosophy of History. Ithaca, N.Y.: Cornell University Press, 1978.

${ }^{17}$ Por exemplo: OLAFSON, Frederik A. Narrative History. In: OLAFSON, Frederik A. The Dialectic of Action. A Philosophical Interpretation of History and Humanities. Chicago/Londres: The University of Chicago Press, 1979; LEMON, M. C. The Discipline of History and the History of Thought. Londres/Nova York: Routledge, 1995.

${ }^{18}$ Por todos: CARR, David. Narrative and the Real World: an Argument for Continuity. History \& Theory, p. $117-131,1986$.

${ }^{19}$ Prova maior é COLLINGWOOD, Robin George. The Idea of History. Oxford: Oxford University Press, 1994 (primeira edição, póstuma, de 1946).

${ }^{20}$ Por exemplo, nos clássicos estudos de WALSH, W. H. An Introduction to Philosophy of History. Londres/ Nova York: Hutchinson's University Library, 1952 [1951]; ATKINSON, R. F. Knowledge and Explanation in History: an Introduction to the Philosophy of History, op. cit..
} 
Danto, William Dray, Louis Mink e W. B. Gallie e outros ligados à chamada filosofia analítica da história, em geral pouco debatida na comunidade acadêmica brasileira; em parte, por causa da irrupção do paradigma linguístico desde os anos 1960, quando filósofos (com sólida formação linguística) deram-se a pensar o conteúdo e a forma da produção historiográfica, o aspecto narrativo dos livros de história, em vez de, como vinham fazendo, colocarem em foco o alcance e o estatuto das afirmaçôes "objetivas" explanatórias ou causais sobre o passado.

Sobre os quatro pontos do debate anteriormente destacados, inextricavelmente conectados, me interessam mais diretamente aqui a primeira e a última proposiçôes, aparentemente antitéticas: (A) a narrativa histórica é um modo de explicação do passado e (D) a narrativa histórica consiste num conjunto de consideraçóes literárias e ficcionais sobre passado.

Como uma hipótese heurística (se a esta altura podemos acreditar em hipóteses!), ${ }^{21}$ a discussão em torno do caráter e da função da narrativa histórica vinha se desenvolvendo numa clave específica por esses autores da filosofia analítica anglo-saxônica, cuja linha de pensamento e argumentaçáo fora nitidamente abandonada em poucos anos com a irrupçáo do paradigma linguístico pós-estruturalista, e, paralelamente das teses do crítico literário norte-americano Hayden White, no início dos anos 1970. Hoje, quando se fala em "questão narrativa", tem-se como que naturalizado pela comunidade dos historiadores (particularmente no Brasil) o background linguístico da questáo, o problema da narratividade como proposto por Hayden White e a "ordem dos discursos" de Foucault, como se o problema tivesse aí sido inaugurado, a partir dessas referências matriciais — e só dentro delas sendo permitido pensar a questão; e como se outra abordagem diversa, imensa e profunda jamais tivesse existido. De modo que a ruptura nessas linhas de reflexão, da filosofia analítica anglo-saxã para o narrativismo - seja oriundo do linguistic turn à francesa, seja da escola linguística de Chicago de White -, acabou obliterando o potencial da reflexão que vinha se desenvolvendo antes que todas suas premissas fossem exauridas. A ascendência meteórica do paradigma pós-estruturalista, que viria a ser chamado "pós-moderno" a partir dos anos 1980, acabou fazendo sombra às discussôes anteriores sobre narrativa e praticamente "naturalizando" suas bases epistemológicas como pressupostos sine qua non para o debate em torno da narrativa. ${ }^{22}$

Durante praticamente todo o século XX as discussóes mais importantes sobre o estatuto filosófico, teórico e/ou epistemológico da história foram feitas praticamente à revelia dos historiadores, que bem pouco contribuíram para alentar esses e outros debates. A natureza

\footnotetext{
${ }^{21}$ As presentes proposiçôes dão base e estão mais detalhadamente sintetizadas no projeto de pesquisa, em andamento, intitulado Em busca do elo perdido. Narrativa e explicação nos filósofos analistas da história, desenvolvido com suporte do CNPq na modalidade PQ.

${ }^{22}$ Os fundamentos epistemológicos do paradigma pós-estruturalista são o antirrealismo e o narrativismo, sumarizados em MALERBA, Jurandir. Teoria e história da historiografia. In: MALERBA, Jurandir. $A$ história escrita. Teoria e história da historiografia. São Paulo: Contexto, 2006.
} 
e função da narrativa é um caso emblemático. Como ensina Rüsen, ${ }^{23}$ durante longas décadas, muito confiantes do potencial científico do ofício que desempenhavam, os debates que atraíam os historiadores giravam majoritariamente em torno de questóes metodológicas. Por ironia, justamente quando eminentes filósofos e críticos literários passaram a dar tratos ao tema, sustentando que a narrativa histórica tem sua base em considerações literárias e ficcionais sobre passado e que, a rigor, é impossível diferenciar o produto do trabalho de um escritor de ficção de uma obra historiográfica, um número cada vez maior de historiadores passou a se interessar por teoria da história, por aquilo que Rüsen chamou de "razão histórica", entendida como o conjunto dos princípios ou fundamentos do pensamento histórico que guiam a atividade do historiador. ${ }^{24}$

Assim posto, os participantes dos debates em torno da narrativa histórica desde a década de 1960 foram, em geral, filósofos e teóricos, mais do que historiadores de ofício, mas a questão da narrativa histórica deveria interessar mais a estes últimos - a nós, historiadores. Como um historiador, meu interesse na filosofia da história é eminentemente prático. Interessa-me conhecer como os debates filosóficos e teóricos podem contribuir para o aprimoramento do campo histórico - como melhor pesquisar, entender e narrar o passado e, por conseguinte, alcançar uma melhor compreensão da história. A maior parte dos historiadores, durante a maior parte do tempo, mas sem muita consciência disso, pensa narrativamente e escreve narrativas. Inclusive por isso, a discussão levada a cabo por filósofos e teóricos sobre o caráter narrativo da escrita histórica deveria interessar diretamente aos historiadores de ofício. E nós temos que estar atentos a esse debate porque aqueles filósofos e teóricos pensam e consideram (valorizam) as coisas que nós historiadores fazemos - as narraçóes que nós escrevemos sobre o passado - como uma atividade séria e importante, portanto, digna de alentar um debate filosófico e teórico. ${ }^{25}$ Apesar das diferenças e mesmo oposiçôes que existem, filósofos e teóricos igualmente consideram a história uma modalidade legítima de conhecimento. Negligenciar esse debate não é uma opção para nós, historiadores.

\footnotetext{
${ }^{23}$ RÜSEN, Jörn. Razão histórica. Teoria da história: os fundamentos da ciência histórica. Brasília: UnB, 2001, p. 45: Assim, "a teoria ganha uma função nova, específica para esse campo, uma função racionalizadora da pragmática textual exercida pela teoria da história na historiografia. A historiografia passa a ser, desse modo, parte integrante da pesquisa histórica, cujos resultados se enunciam, pois, na forma de um "saber redigido".

${ }^{24}$ RÜSEN, Jörn. Studies in Metahistory. Pretória: Humana Sciences Research Council, 1993; RÜSEN, Jörn. Historical Narration: Foundation, Types, Reason. History and Theory, Beiheft, n. 26, p. 87-97, 1987; RÜSEN, Jörn. Razão histórica. Teoria da história: os fundamentos da ciência histórica, op. cit.

${ }^{25}$ Lembremos apenas a obra de um Paul Ricouer, uma vida dedicada praticamente a tais questôes. Cf. RICCEUR, Paul. La Mémoire, L'Histoire, L'Oubli, op. cit.; RICCEUR, Paul. Narrative Time. Critical Inquiry, v. 7, p. 169-90, 1980; RICCEUR, Paul. Tempo e narrativa. Trad. Constança M. César. Campinas: Papirus, 1994-96. 3v.; RICEEUR, Paul. The Model of the Text: Meaningful Action Considered as a Text. New Literary History, n. 5, p. 91-117, 1983.
} 


\section{Para uma "genealogia" do debate em torno à narrativa histórica}

Uma vez formulado meu argumento geral, é meu propósito passar em revista, a seguir, algumas peças-chave do debate sobre narrativa histórica tal como levado a efeito dentro da filosofia da história, com vistas ao estabelecimento de um novo desenho da árvore genealógica do debate na narrativa, um mapeamento mais inclusivo da questão que contemple linhagens de reflexão diversas — e quiçá anteriores e contemporâneas — ao narrativismo da tradição pós-linguística. Essa revisão tem o propósito de servir-me de um guia de pesquisa e, ao mesmo tempo, servir de orientação e chamariz para futuros debates e pesquisas na área.

Remontando à base de toda discussão dos filósofos analíticos, uma obra germinal a ser referida é o clássico The Idea of History, de R. G. Collingwood. Louis Mink dedica toda uma obra ao estudo de suas proposiçôes. ${ }^{26}$ A rigor, de toda vasta obra The Idea of History, somente a grande seção final, intitulada "Epilegomena," é realmente relevante para as questôes teóricas pertinentes à narrativa. A longa parte que a antecede, sobre a história da historiografia, é muito datada e em grande parte superada. Porém, este é reconhecidamente um dos trabalhos mais influentes de teoria da história do século XX. ${ }^{27}$ Praticamente todos os filósofos mencionados a seguir são tributários das reflexóes de Collingwood.

O longo e denso Narration and Knowledge, de Arthur Danto, não foi, à época de seu lançamento, um livro aclamado pela crítica, mas seguramente é um das grandes contribuiçóes à filosofia da história publicadas nos Estados Unidos. Trata-se de um trabalho inovador, cujas lições vêm sendo absorvidas e discutidas até hoje. Apresenta-se como uma alternativa à teoria das covering laws [termo traduzido como "leis de cobertura" ou "leis gerais"] de Hempel e Oppenheim, ${ }^{28}$ ao defender que a narrativa já é em si uma forma de explicação. Segundo

\footnotetext{
${ }^{26}$ MINK, Louis O. Mind, History, and Dialectic: The Philosophy of R. G. Collingwood. Bloomington: Indianna University Press, 1969.

${ }^{27}$ COLLINGWOOD, Robin George. The Idea of History, rev. edition, with Lectures 1926-1928, ed. Jan Van der Dussen. Oxford: Oxford University Press 1994. (Primeira edição de 1946). Também seu COLLINGWOOD, Robin George. An Autobiography. Oxford: Oxford University Press, 1939. Cf. e ARRAIS, Cristiano. Robin George Collingwood. In: MALERBA, Jurandir (Org.). Liçôes de história: o caminho da ciência no longo século XIX. Porto Alegre/Rio de Janeiro: Edipucrs/FGV, 2010.

${ }^{28}$ HEMPEL, Carl Gustav; OPPENHEIM, Paul. Studies in the Logic of Explanation. Philosophy of Science, n. 15, p. 135-75, 1948; reproduzido em HEMPEL, Carl Gustav. Aspects of Scientific Explanation. Nova York: Free Press, 1965. O método ou modelo dedutivo-nomológico é uma visão formalizada da explicação científica em linguagem natural. Caracteriza as explicaçóes científicas primariamente como argumentos dedutivos com ao menos uma lei natural entre as premissas. As sentenças que formulam a informação explanatória são as sentenças explanans e seu conjunto é o explanantia. A conclusão do explanans é o explanandum. Os componentes do explanans são as leis, ou teorias explicativas, e as condiçôes iniciais, enquanto que o fato a ser comprovado é o explanandum. O modelo Popper-Hampel é a manifestaçáo maior da crença na existência de um único método científico universal a que todas as ramificaçôes científicas devem se subsumir. Um esboço disso pode ser encontrado em POPPER, Karl. The Logic of Scientific Discovery. Londres: Hutchinson, 1959. Cf. MAYES, Randolph Gregory. Theories of Explanation. In: The Internet Encyclopedia of Philosophy, 2006.
} 
Danto, "A diferença entre história e ciência não é a de que a história não aplica e a ciência aplica esquemas organizativos que vão além do dado. Ambas fazem-no. A diferença tem a ver com o tipo de esquema organizativo empregado por cada uma delas. A História conta estórias". Segundo Danto o passado não é fixo e determinado, ao contrário, uma espécie de "realinhamento retroativo do passado" tem lugar na historiografia. ${ }^{29}$

Uma obra que ainda é referência na área de teoria da história no Brasil é a velha antologia organizada por Patrick Gardner, Theories of History. Trata-se da mais importante coleção de ensaios sobre a "filosofia analítica da história" (Parte II, "Explicação e Leis"), que contém muitos dos debates cruciais dessa vertente, como, por exemplo, "A funçấo das leis gerais em História", de Hempel, "A explicação histórica", de Morton White, e outros ensaios importantes sobre o debate do modelo das covering laws em autores como Ernest Nagel, W. B. Gallie, William Dray, Charles Frankel, Alan Donagan e Michel Scriven. ${ }^{30}$

No debate sobre o papel da narrativa em curso na década de 1960, destaca-se a obra de W. B. Gallie. Seu Philosophy and the Historical Understanding, ${ }^{31}$ hoje talvez já considerado passé, foi um trabalho pioneiro quando surgiu em 1964. O argumento de Gallie, especialmente exposto em seu clássico ensaio "The Historical Understand”, é que a narrativa é o modo de explanação histórica por excelência; para acompanhar o conteúdo explanatório de um escrito histórico, o leitor deve ser capaz de compreender o enredo da estória onde tal explanação está contida, ou seja, fundamental para a compreensão histórica é a habilidade do leitor de seguir estórias, entendidas como sequências de incidentes aceitáveis embora não previsíveis que confluem para uma conclusão prometida, embora sempre aberta. Relatos de açôes particulares de homens individuais (a preocupação central dos historiadores) devem invocar fatos institucionais sobre a vida societal. ${ }^{32}$

Disponível em: <http://www.iep.utm.edu/e/explanat.htm>; NIINILUOTO, Ilkka. Covering Law Model. In: AUDI, Robert (Ed.). The Cambridge Dictionary of Philosophy. Nova York: Cambridge University Press, 1995; SALMON, Wesley. Four Decades of Scientific Explanation. Minnesota: University of Minnesota Press, 1990; WOODWARD, James. Scientific Explanation. In: The Stanford Encyclopedia of Philosophy, 1990. Disponível em: <http://plato.stanford.edu/entries/scientific-explanation/>.

${ }^{29}$ Cf. DANTO, Arthur C. Narration and Knowledge (including the integral text of Analytical Philosophy of History). Nova York: Columbia University Press, 1965, p. 111 e p. 168, respectivamente. Sua obra foi discutida por muitos autores, inclusive Mink, por isso nosso interesse direto nele. MINK, Louis. Philosophical Analysis and Historical Understanding. In: Historical Understanding; Roth, Narrative Explanations e Ricœur, Time and Narrative, n. 1, p. 143-49. Também Danto, Historical Language and Historical Reality, texto adicionado à edição de 1985 de Narration and Knowledge.

${ }^{30}$ GARDINER, Patrick (Ed.). Theories of History. Nova York: Free Press, 1959. Há uma tradução para o português publicada pela Fundação Calouste Goulbenkian, de Lisboa. Também GARDINER, Patrick. The Nature of Historical Explanation, op. cit.

${ }^{31}$ GALLIE, Walter Bryce. Philosophy and the Historical Understanding. 2. ed. Nova York: Schocken, 1968. A primeira edição é de 1964 .

${ }^{32}$ GALLIE, Walter Bryce. The Historical Understanding, op. cit. (reeditado como Narrative and Historical Understanding). In: ROBERTS, Geoffrey (Ed.). The History and Narrative Reader, op. cit.. Cf. MINK, Louis. The Autonomy of Historical Understanding. History and Theory, n. 5, p. 24-47, 1965. Ricoer também discute Gallie em Tempo e narrativa, v. 1, p. 150 e ss. 
Um autor que vem sendo seminal para a reflexão no campo da teoria da história e especificamente sobre narrativa há mais de quatro décadas é William $\mathrm{H}$. Dray. Sua inserção no debate deu-se com um breve e denso ensaio, que também respondia ao modelo das covering laws proposto por Hempel. Law and Explanation in History faz uma abrangente abordagem daquele modelo, sua argumentação, fundamentação teórica e recepção. Dray sustenta que esse modelo é tão enganoso que deveria ser definitivamente abandonado no debate sobre a lógica da explicação em história. A densidade, síntese e clareza do ensaio de Dray o mantém como obra digna de leitura até hoje. Ele é especialmente proveitoso como uma introdução à literatura anterior, importante para o debate do modelo das covering laws, incluindo os filósofos ditos "idealistas" da história, como Michael Oakeshott e Collingwood. Esse livro de Dray, junto com alguns outros ensaios dispersos, foi em grande medida decisivo para a superação do modelo hempeliano. ${ }^{33}$

Em texto clássico publicado na revista History and Theory, de 1971, William Dray aborda a natureza e a função da narrativa na historiografia, afirmando não haver conexão necessária entre as ideias da história e as da narração. Para Dray, o trabalho histórico deveria ser explicativo, mas a narrativa não é em si mesma uma forma de explicação. A narrativa torna-se explicativa quando pode incorporar contingências, entendidas como condiçóes necessárias, em vez de causas. A história, ao contrário da ciência, esforça-se por uma unidade sintética, em vez da remoçấo de toda contingência de seu objeto. O papel da narrativa se realiza ao atingir essa unidade, que merece uma maior atenção filosófica. Sua reflexão avança sob a luz crítica do pensamento de Walsh, Gallie e Morton White. Dray marcou definitivamente seu lugar na teoria da história contemporânea por sua magistral interpretação da concepção de história em Collingwood. Muitos autores consideram History as Re-enactment como o melhor estudo já realizado sobre a obra desse autor fundamental para as discussōes em torno da narrativa histórica. ${ }^{34}$

Embora tendo recebido uma carga de crítica maior do que muitos partícipes do debate sobre a natureza e função da narrativa na filosofia analítica da história, a obra do eminente filósofo Maurice Mandelbaum representa uma posição particular no debate, e que muitos ainda levam em séria consideração. Mandelbaum concebe "infeliz" a tentativa de ligar história e narrativa. Seria infeliz porque essa ligação enfatiza o que é, rigorosamente falando, um aspecto meramente incidental da investigação histórica. Para Mandelbaum, a estrutura narrativa é um mero instrumento estilístico. Ele se apoia numa imagem quase rankeana do

33 DRAY, William Herbert. Laws and Explanation in History. Oxford: Oxford University Press, 1957. Ver o ensaio crítico de PASSMORE, John. Explanation in Everyday Life, in Science, and in History. In: GEORGE, Nadel. Studies in the Philosophy of History. Nova York: Harper \& Row, 1965. O livro de Dray é exaustivamente discutido em RICCEER, Paul. Tempo e Narrativa, volume 1, p. 121-31. Também DRAY, William Herbert. Philosophy of History, op. cit.

${ }^{34}$ Cf. DRAY, William Herbert. History as re-enactment: $R$. G. Collingwood's idea of history. Oxford: Clarendon Press, 1995. Também o importante estudo de MINK, Louis. Mind, History, and Dialectic: The Philosophy of R. G. Collingwood, op. cit. 
historiador recontando o passado "tal como aconteceu". Sua analogia de referência assemelha a história com a produção de mapas. A estória do passado precisaria apenas ser comunicada, não construída. A objeção metafísica a explicaçôes narrativas em história pressupóe a irrefutabilidade da concepção de um passado objetivamente descritível. ${ }^{35}$

Suas concepçóes foram inicialmente desenhadas em artigo veiculado nas páginas de History \& Theory em 1967, quando Mandelbaum propõe que, ao colocarem ênfase demasiada no aspecto narrativo da história, os historiadores acabam negligenciando o papel da pesquisa e da descoberta. O entendimento, compartilhado por Gallie, Danto e outros, da história como uma narrativa construída seria para ele muito simplista e diminui o papel da averiguação e da descoberta. A história não se resume a recontar uma sequência linear de açôes humanas inteligíveis, mas implica a análise de um complexo padrão de mudança. A relação fundamental seria entre parte e todo, não antecedente e consequente. ${ }^{36}$

Louis Mink é em geral reconhecido como uma figura-chave no debate filosófico sobre história e narrativa. Numa série de importantes ensaios publicados na década de 1960, a maioria deles reeditados em Historical Understanding, Mink abriu o terreno que seria mais firme e radicalmente ocupado por autores posteriores como Hayden White e Frank. R. Ankersmit. Em primeiro lugar, Mink foi um proponente precoce da perspectiva de que a narrativa é central para o trabalho histórico. Em 1962, ele afirmava:

As conclusóes significativas dos argumentos históricos estão engastadas ou incorporadas na estrutura narrativa da própria escritura histórica; elas não são proposições para as quais a história fornece um complemento de evidências, o modo específico por meio do qual a evidência é discursivamente ordenada. ${ }^{37}$

Mink insistia também que "a narrativa é a forma típica, senão universal de historiografia”. Além disso:

É a forma por meio da qual os resultados da investigaçẫo histórica são diretamente relatados. É a própria história narrativa que reivindica ser uma contribuição ao conhecimento, não alguma coisa mais que a história narrativa meramente organiza ou populariza. A exigência de uma

\footnotetext{
${ }^{35}$ Cf. MANDELBAUM, Maurice. The Anatomy of Historical Knowledge. Baltimore: Johns Hopkins University Press, 1977. Comparar, nesse aspecto, o "Ideal Chronicler" de Danto em Narration and Knowledge. Ver também MANDELBAUM, Maurice. The problem of historical knowledge: an answer to relativism. Nova York: Liveright, 1938. Uma nova edição, com um prefácio inédito pelo autor, foi publicada pela Harper \& Row em 1967. Esta foi sua clássica resposta às teorias relativistas que circulavam nos anos 1930, uma obra de impacto quando de seu lançamento, que continuou a repercutir nos debates da década de 1960 em diante, como dá mostras a obra de Mink.

${ }^{36}$ MANDELBAUM, Maurice. A Note on History and Narrative, History \& Theory, n. 3, p. 413-419, 1967, também reproduzido em ROBERTS, Geoffrey. (Ed). The History and Narrative Reader, op. cit.

${ }^{37}$ MINK, Louis O. Historical Understanding. Ithaca/Londres: Cornell University Press, 1987, p. 12.
} 
história narrativa é a de que sua estrutura é uma contribuição ao conhecimento, não um apenas um mero artefato literário para a apresentação de uma série de descrições factuais. ${ }^{38}$

Para Mink, a narrativa é em si um modo de compreensão, ou, como ele coloca em "Narrative Form as a Cognitive Instrument”, um “instrumento cognitivo", um meio de ver e entender as coisas em conjunto, em sua unidade. Por isso afirma Mink que "A função cognitiva da forma narrativa não é apenas a de narrar uma sucessão de eventos, mas de apresentar um conjunto de inter-relações de variados tipos como um todo singular”. No discurso histórico, diz-se desse conjunto de relaçóes que ele representa uma parte da realidade passada. Mas, objeta Mink, a narrativa é um "produto da construção imaginativa, que não pode defender qualquer reivindicação à verdade por qualquer procedimento aceito de argumentação ou autenticação" 39

\section{Considerações finais}

$\mathrm{O}$ argumento de que a narração histórica é primordialmente um ato de contar estórias, não de pesquisa, descoberta e explicação dos fatos passados, é um dos temas mais importantes do que se convencionou chamar "narrativismo", ou a proposta construtivista do texto histórico a partir da ênfase em seus protocolos linguísticos, magistralmente sintetizado nos escritos de Hayden White. ${ }^{40}$ Em seu famoso ensaio "The Historical Text as Literary Artifact", White caracteriza as narrativas históricas como "ficçôes verbais, cujo conteúdo é tanto inventado como encontrado e cujas formas têm mais em comum com suas contrapartidas na literatura do que na ciência”. ${ }^{41}$ A fonte da invenção da ficção verbal que constitui uma narrativa histórica é o que White chama de emplotment — ou a escolha do historiador de colocar sua estória num enredo ou outro. Essa é uma das linhas de força do chamado "narrativismo". Rios de tinta já jorraram em torno das teses narrativistas, em seu favor ou desabono, e não é o caso retomá-las aqui. Devemos por ora guardar que são referência central para o debate em torno da narrativa. Nossa proposta, ao longo de pesquisas futuras, é justamente demonstrar que este é um, de modo algum o único modo de pensar a questão narrativa. Como procurei sumarizar na breve análise bibliográfica anteriormente mencionada, entre as discussóes que se vinham travando entre os filósofos analíticos, — como Dray,

\footnotetext{
${ }^{38}$ MINK, Louis. The Divergence of History and Sociology in Recent Philosophy of History. In: Historical Understanding, op. cit., p. 168.

${ }^{39}$ MINK, Louis. History and Fiction as Modes of Comprehension; Narrative Form as Cognitive Instrument, ambos em Historical Understanding.

${ }^{40}$ Como os clássicos Metahistory (1973), Tropics of Discourse (1978), The Content of the form (1987) e Figural Realism (1999), todos publicados pela Johns Hopkins University Press (Baltimore).

${ }^{41}$ WHITE, Hayden. The Historical Text as Literary Artifact. In: CANARY, Robert H.; KOZICKI, Henry. The Writing of History. Madison, Wisc.: Wisconsin University Press, 1978, p. 41-62, reproduzido em ROBERTS, Geoffrey (Ed.). The History and Narrative Reader, op. cit.
} 
Gallie, Mandelbaum, Danto, Morton White, Ely — interlocutores de Mink, e entre esse mesmo autor e os narrativistas que lhe são posteriores (White e seus discípulos: Ankersmit, Kelner, Jenkins, Berkhoffer Jr.), o debate em torno da natureza e do papel da narrativa no trabalho do historiador sofre um imenso deslocamento. Nosso propósito é justamente recuperar as premissas daquele debate em torno da narrativa que foi abandonado em prol da proposta narrativista, pós-moderna, que se instaurou como a única via legítima do debate.

\section{Referências bibliográficas}

ANKERSMIT, Frank Rudolf. Six Theses on Narrativist Philosophy of History. In: ANKERSMIT, Frank Rudolf. History and Tropology. Berkeley: Universiy of California Press, 1994a.

. Historical Representation. Stanford: Stanford University Press, 2001.

. History and Tropology. Berkeley: Universiy of California Press, 1994a.

. History and Tropology: The Rise and Fall of Metaphor. Berkeley: University of California Press, 1994b.

. Meaning Truth, and Reference in Historical Representation. Ithaca, NY: Cornell University Press, 2012.

. Narrative Logic: A Semantic Analysis of the Historian's Language. The Hague: Nijhoff, 1983.

. Reply to professor Roth: on how antidogmatism bred dogmatism. Rethinking History: The Journal of Theory and Practice, v. 17, n. 4, p. 570-585, 2013.

. The Dilemma of Contemporary Anglos-Saxon Philosophy of History. History \& Theory, n. 25, p. 26, 1986.

ANKERSMIT, Frank Rudolf; KELLNER, Hans. A New Philosophy of History. Londres: Reaktion, 1985.

ARRAIS, Cristiano. Robin George Collingwood. In: MALERBA, Jurandir (Org.). Liçôes de história: o caminho da ciência no longo século XIX. Porto Alegre/Rio de Janeiro: Edipucrs/ FGV, 2010.

ATKINSON, R. F. Knowledge and Explanation in History: an Introduction to the Philosophy of History. Ithaca, N.Y.: Cornell University Press, 1978.

BATISTA, Micheline. Hermenêutica filosófica e o debate Gadamer-Habermas. Crítica e Sociedade: Revista de Cultura Politica, v. 2, n. 1, jan./jun. 2012.

BERKHOFER Jr., Robert. "The Chellenge of Poetics to (Normal) Historical Practice". In: JENKINS, Keith (Org.). The postmodern History reader. Londres/Nova York: Routledge, 1997. 
CARR, David. Narrative and the Real World: an Argument for Continuity. History \& Theory, p. 117-131, 1986.

CARRARD, Philippe. Poetics of the New History: French Historical Discourse from Braudel to Chartier. Baltimore: Johns Hopkins University Press, 1992.

COLLINGWOOD, Robin George. An Autobiography. Oxford: Oxford University Press, 1939.

COLLINGWOOD, Robin George. The Idea of History. Oxford: Oxford University Press, 1994.

DANTO, Arthur C. Narration and Knowledge. Nova York: Columbia University Press, 1965. DRAY, William Herbert. Laws and Explanation in History. Oxford: Oxford University Press, 1957.

. Philosophy of History. Nova York: Prentice-Hall, 1964.

. History as re-enactment: R. G. Collingwood's idea of history. Oxford: Clarendon Press, 1995.

GADAMER, Hans-Georg. Verdade e método. Petrópolis: Vozes, 2001/2002. 2v.

GALLIE, Walter Bryce. Philosophy and the Historical Understanding. 2. ed. Nova York: Schocken, 1968.

. The Historical Understanding. History \& Theory, v. 3, n. 2, p. 149-202, 1963.

GARDINER, Patrick (Ed.). Theories of History. Nova York: Free Press, 1959.

. The Nature of Historical Explanation. Oxford: Oxford University Press, 1952.

GRONDIN, Jean. Introducción a la hermenêutica filosófica, Barcelona: Herder, 2002.

GUADARRAMA, José Luís. El debate Gadamer-Habermas: interpretar o transformar el mundo. Contribuciones desde Guatepec, n. 10, p. 11-21, jan./jun., 2006.

HABERMAS, Jürgen. La lógica de las ciencias sociales. Madri: Tecnos, 1988.

HEKMAN, Susan Jean. O debate Gadamer-Habermas. In: HEKMAN, Susan Jean. Hermenêutica e sociologia do conhecimento. Lisboa: Ediçóes 70, 1986, p. 187-198.

HEMPEL, Carl Gustav. Aspects of Scientific Explanation. Nova York: Free Press, 1965.

HEMPEL, Carl Gustav; OPPENHEIM, Paul. Studies in the Logic of Explanation. Philosophy of Science, n. 15, p. 135-75, 1948.

HUMBOLDT, Wilhelm von. Sobre a tarefa do historiador. Traduçáo Pedro Caldas. Anima: História, Teoria e Cultura. Rio de Janeiro/Curitiba, ano 1, n. 2, p. 79-89, 2001.

IGGERS, Georg. La ciencia histórica en el siglo XX. Las tendencias actuales. Barcelona: Paidós, 1995.

JENKINS, Keith. Introduction: On Being Open about our Closures. In: JENKINS, Keith (Org.). The postmodern History reader. Londres/Nova York: Routledge, 1997. 
KELLNER, Hans. Language and Historical Representation: Getting the Story Crooked. Madison: University of Wisconsin Press, 1989.

KOSELLECK, Reinhart; GADAMER, Hans-Georg. Historia y hermenéutica. Barcelona: Paidós, 1997.

LEMON, M. C. The Discipline of History and the History of Thought. Londres/Nova York: Routledge, 1995.

MALERBA, Jurandir. Liçóes de história. Da história científica à crítica da razão metódica. Porto Alegre/Rio de Janeiro: EdiPucrs/Editora FGV, 2013.

. Teoria e história da historiografia. In: MALERBA, Jurandir. A história escrita. Teoria e história da historiografia. São Paulo: Contexto, 2006.

MANDELBAUM, Maurice. A Note on History as Narrative, History \& Theory, n. 3, p. 413-419, 1967.

. The Anatomy of Historical Knowledge. Baltimore: Johns Hopkins University Press, 1977. 1938.

MARTINS, Estevão C. R. A história pensada. São Paulo: Contexto, 2009.

MAYES, Randolph Gregory. Theories of Explanation. In: The Internet Encyclopedia of Philosophy, 2006. Disponível em: <http://www.iep.utm.edu/e/explanat.htm>.

MINK, Louis O. Historical Understanding. Ithaca/Londres: Cornell University Press, 1987, p. 12.

. Mind, History, and Dialectic: The Philosophy of R. G. Collingwood. Bloomington: Indianna University Press, 1969.

. The Autonomy of Historical Understanding. History and Theory, n. 5, p. 24-47, 1965.

NIINILUOTO, Ilkka. Covering Law Model. In: AUDI, Robert (Ed.). The Cambridge Dictionary of Philosophy. Nova York: Cambridge University Press, 1995.

OLAFSON, Frederik A. Narrative History. In: OLAFSON, Frederik A. The Dialectic of Action. A Philosophical Interpretation of History and Humanities. Chicago/Londres: The University of Chicago Press, 1979.

PASSMORE, John. Explanation in Everyday Life, in Science, and in History. In: GEORGE, Nadel. Studies in the Philosophy of History. Nova York: Harper \& Row, 1965.

POPPER, Karl. The Logic of Scientific Discovery. Londres: Hutchinson, 1959.

RANKE, Leopold von. Sobre o caráter da ciência histórica. Tradução Julio Bentivoglio. In: MALERBA, Jurandir. Liçóes de história. O caminho da ciência no longo século XIX. Porto Alegre/Rio de Janeiro: EdiPucrs/Editora FGV, 2010, p. 141. 
RICEUR, Paul. Del texto a la acción. México: Fondo de Cultura Económica, 2002. . La Mémoire, L'Histoire, L'Oubli. Paris: Éditions du Seuil, 2000, p. 169-171. . Narrative Time. Critical Inquiry, v. 7, p. 169-90, 1980. . Tempo e narrativa. Trad. Constança M. César. Campinas: Papirus, 1994-96. 3v. . The Model of the Text: Meaningful Action Considered as a Text. New Literary History, n. 5, p. 91-117, 1983.

. Time and Narrative. Chicago: Chicago University Press, 1990, v. 1, p. 143-149.

ROBERTS, Geoffrey (Ed.). The History and Narrative Reader. Londres/Nova York: Routledge, 2001.

ROTH, "Narrative Explanations: the case of history" History and Theory, v. 27, n. 1, 1988, p. 1-13.

ROTH, Paul A. Whistling history: Ankersmit's neo-Tractarian theory of historical representation. Rethinking History: The Journal of Theory and Practice, v. 17, n. 4, p. 548556, 2013.

RÜSEN, Jörn. Historical Narration: Foundation, Types, Reason. History and Theory, Beiheft, n. 26, p. 87-97, 1987.

. Razão histórica. Teoria da história: os fundamentos da ciência histórica. Brasília: UnB, 2001.

. Studies in Metahistory. Pretória: Humana Sciences Research Council, 1993.

SALMON, Wesley. Four Decades of Scientific Explanation. Minnesota: University of Minnesota Press, 1990

WALSH, W. H. An Introduction to Philosophy of History. Londres/Nova York: Hutchinson's University Library, 1952 [1951].

WHITE, Hayden. The Historical Text as Literary Artifact. In: CANARY, Robert H.; KOZICKI, Henry. The Writing of History. Madison, Wisc.: Wisconsin University Press, 1978, p. 41-62.

WOODWARD, James. Scientific Explanation. In: The Stanford Encyclopedia of Philosophy, 1990. Disponível em: < http://plato.stanford.edu/entries/scientific-explanation/>. 